\title{
Evaluación de dietas bajas en proteina suplementadas con Dl-Metionina y L-Lisina sobre el comportamiento productivo de patas criollas (Cairina moschata doméstica L.)
}

\section{Evaluation of decreased protein diets supplemented with DL-Methionine and L-Lysine on muscovy ducks productive performance (Cairina moschata domestica L.)}

\author{
Pedro Ciriaco C. ${ }^{1}$; Víctor Vergara R. ${ }^{2}$
}

\begin{abstract}
Resumen
Se evaluó el rendimiento productivo de patas criollas en etapas de desarrollo (0-20 semanas) y postura (21-44 semanas), alimentadas con dietas bajas en proteína y suplementadas con los aminoácidos sintéticos DL-Metionina y L-Lisina. Se distribuyeron al azar 240 patas en desarrollo y 72 en postura en cuatro tratamientos $(\mathrm{T} 1=$ dieta control, $\mathrm{T} 2=$ dieta disminuida en proteína total sin suplementación de aminoácidos, T3= Dieta disminuida en proteína solo con suplementación de metionina, T4= dieta disminuida en proteína con suplementación de metionina y lisina). Los parámetros evaluados fueron: peso corporal, ganancia de peso, consumo de alimento, ingestión de proteína, metionina y lisina; conversión alimenticia, numero de huevos por pata por día, peso promedio de huevos, masa de huevos, porcentaje de postura; asimismo, se determinó el balance de nitrógeno en las dos etapas. Las aves que recibieron la dieta baja en proteína, pero suplementada con DL-Metionina y HCL-Lisina, tuvieron el mejor rendimiento productivo y económico en la etapa de desarrollo; sin embargo, en la etapa de postura, no se presentó la misma respuesta y la retribución económica fue negativa. Por otro lado, todos los balances de nitrógeno fueron positivos y se recomendó utilizar las dietas bajas en proteína suplementándolas con los aminoácidos sintéticos en estudio.
\end{abstract}

Palabras clave: desarrollo; lisina; metionina; pata criolla; postura.

\begin{abstract}
We evaluated the productive performance in female Muscovy ducks in developmental (0-20 weeks) and laying (21-44 weeks) stages, fed with decreased protein diets and supplemented with DL-Methionine and L-Lysine. Two hundred forty female ducks in growth and 72 in laying stage were randomly distributed into four treatments $(\mathrm{T} 1=\mathrm{control}$ diet, $\mathrm{T} 2=$ decreased protein diet without amino acid supplementation, T3= decreased protein diet supplemented with methionine alone, T4= decreased protein diet supplemented with methionine and lysine). The parameters evaluated were: body weight, body weight gain, feed consumption; protein ingestion, methionine and lysine intake; feed conversion, number of eggs/duck/day, average egg weight, eggs mass and percentage of egg laying. We also determined the nitrogen balance in both stages. Female ducks given the decreased protein diet but supplemented with DL-Methionine and L-Lysine had the best productive and economic performance in the developmental stage. However, during the laying period, we didn't get the same result and the economical retribution was negative. On the other hand, since all nitrogen balances were positive it is recommended to use decreased protein diets supplemented with the synthetic amino acids under study.
\end{abstract}

Key words: development; lysine; methionine; Muscovy female duck; laying.

\section{Introducción}

La escasez de insumos proteicos y su constante elevación de precios obliga a buscar posibilidades de nutrición equivalente y de menor costo, dentro de ello se halla el uso de aminoácidos sintéticos. Hay diferencias en el contenido de los aminoácidos de proteínas de distintas fuentes, de modo que algunos pueden tener niveles bajos de algún aminoácido esencial, razón por la cual las carencias de una proteína se compensan intercambiándola con otra o suministrando un aminoácido sintético (Church, 1992;
Rojas, 1994). La DL-Metionina y el L-Lisina son los aminoácidos sintéticos más utilizados en la dieta de las aves. La suplementación en las dietas puede sustituir las deficiencias de los insumos con bajos niveles de estos nutrientes, mejorando de esta manera el valor nutritivo de las dietas y disminuyendo relativamente los costos (Leclercq, 1998). La DL-Metionina se suplementó en dietas disminuidas en proteína total de 19 a $17 \%$ en desarrollo y de 14 a $12 \%$ en postura de gallinas ponedoras, encontrándose respuestas positivas, estadísticamente, en

\footnotetext{
1. Docente Principal, Departamento de Producción Animal, Facultad de Zootecnia. Universidad Nacional Agraria La Molina, Lima, Perú. Email: pciriaco@lamolina.edu.pe

2. Docente Principal, Departamento de Nutrición, Facultad de Zootecnia. Universidad Nacional Agraria La Molina, Lima, Perú.

Email: vjvergara@lamolina.edu.pe
} 
el rendimiento productivo y económico comparado con la dieta control (Lillie etal., 1974). Asimismo, Maurice, Hugheset al. (1982), disminuyeron los niveles de proteína, de 18 a $13 \%$, en dietas de desarrollo de gallinas usando suplementos de DL-Metionina y L-Lisina, no encontrando diferencias significativas en el rendimiento productivo y no observando un efecto negativo en el inicio de la fase de postura del ave.

Leeson y Summers (1982) disminuyeron la proteína de 16 a $14 \%$ en dietas de pollonas con suplementos de DL-Metionina y L-Lisina y observaron que no afectó el porcentaje de postura, el peso del huevo y la calidad de la cáscara de las gallinas en la etapa de postura. Asimismo, Keshavarz y Austic (1985) reportaron que la producción de huevos, su peso y tamaño, no fueron afectados cuando se suministró a las aves dietas con bajo nivel de proteína $(14,4 \%)$, pero con suplementos de DL-Metionina.

Keshavarz y Jackson (1992) colocaron suplementos de DL-Metionina y L-Lisina en dietas en desarrollo y postura bajas en proteína total; pero, no encontraron diferencias significativas en el porcentaje de postura y en el peso de huevo. Andrade, Leandro y Stringhini (2003) disminuyeron la proteína total de 17 hasta $14 \%$, introduciendo suplementos de DL-Metionina y L-Lisina en ponedoras; no se encontraron diferencias significativas para el porcentaje de postura, el consumo de alimento, el peso y calidad del huevo y el peso corporal al final de postura. Sin embargo, en un trabajo experimental en la universidad de Clemson, se disminuyó la proteína de 17 a $15 \%$, en dietas de gallinas ponedoras, usando suplementos de DLMetionina y L-Lisina; en este caso, no se vio afectado el porcentaje de postura, el peso promedio del huevo y el consumo del alimento; además, se obtuvo una mayor retribución económica usando las dietas suplementadas con los dos aminoácidos sintéticos (Ajinomoto Biolatina, 2005).

En ponedoras alimentadas con diferentes niveles de proteína $(12,1416$ y $18 \%$ ), se encontró que el balance de nitrógeno no se vio afectado, sin embargo el consumo y excreción de nitrógeno tuvieron valores incrementados en la medida en que la proteína aumentaba. El coeficiente de metabolización aparente del nitrógeno se mostró más eficiente para el nivel del $12 \%$ de proteína, evidenciando un mejor aprovechamiento del nitrógeno. Asimismo, las ponedoras excretaron menos nitrógeno con el menor nivel de proteína (Rizzo et al., 2004).

El objetivo del presente trabajo es evaluar el efecto de las dietas bajas en proteínas suplementadas con DL-Metionina y L-Lisina, en etapas de desarrollo y postura de patas criollas, medido a través de: peso corporal, ganancia de peso, consumo de alimento, proteína, metionina y lisina; conversión alimenticia, número total de huevos por pata por día, peso del huevo, masa de huevo, porcentaje de postura, balance de nitrógeno y el mérito económico.

\section{Materiales y métodos}

La investigación se realizó en el proyecto Aves-Patos del Instituto Nacional de Investigación Agroindustrial (INIA)
La Molina, del Ministerio de Agricultura, y los análisis químicos fueron realizados en el laboratorio de evaluación nutricional de la Universidad Nacional Agraria La Molina. Se emplearon 12 unidades experimentales para la etapa de desarrollo de $5 \mathrm{~m}^{2}$ y $6 \mathrm{~m}^{2}$ para postura, alojando 20 patitas por unidad hasta las 20 semanas de edad y 6 patas hasta las 44 semanas de edad. Las unidades experimentales se establecieron dentro de un galpón de tipo abierto controlándose la ventilación de las aves; asimismo, se realizó el manejo siguiendo las recomendaciones para la raza de patas en estudio, contándose con los equipos de crianza adecuados.

Para evaluar el contenido de nitrógeno en las heces, se utilizó una batería de cuatro jaulas de $0,25 \mathrm{~m}^{2}$, alojándose 24 patas en desarrollo y 16 patas en postura. En la fase de postura se utilizaron nidales de latón de 10 compartimientos, un nidal para cada uno de los tratamientos, siendo las dimensiones de cada nido de $30 \mathrm{~cm}$ de ancho x $30 \mathrm{~cm}$ de altura y $35 \mathrm{~cm}$ de profundidad; asimismo, se utilizó una balanza tipo reloj para el pesaje semanal de las patas y una balanza digital para pesar los huevos. Las reglas de bioseguridad fueron efectuadas adecuadamente.

Las dietas se formularon en base a las recomendaciones nutricionales del Instituto Nacional para la Investigación Agronómica (INRA, 1984), las cuales se muestran en la Tabla 1, con suministro del alimento ad libitum. Se utilizó el Diseño Completamente al Azar, con cuatro tratamientos y tres repeticiones, y la comparación entre promedios se realizó mediante la prueba de Duncan (Calzada, 1981). El balance de nitrógeno se midió por diferencia entre el nitrógeno ingerido y excretado, durante un periodo de siete días, medidos en $\mathrm{g} / 100 \mathrm{~g}$ de muestra.

Los parámetros evaluados fueron: peso corporal, ganancia de peso, consumo de alimento, ingestión de proteína, lisina y metionina; conversión alimenticia en desarrollo y postura, porcentaje de postura, número de huevos por pata por día, peso promedio del huevo, masa de huevo y balance de nitrógeno.

\section{Resultados y discusión}

En la Tabla 2 se puede apreciar que se encontraron diferencias significativas en todos los parámetros evaluados; se obtuvo los mayores pesos corporales, menores consumos de alimento y una mejor conversión alimenticia en las aves alimentadas con la dieta control y con la dieta disminuida en proteína, suplementada con DL-Metionina y L-Lisina. Estos resultados demuestran que las aves pudieron cubrir sus requerimientos con los aminoácidos suplementados y se obtuvieron resultados positivos, lo que concuerda con Maurice et al. (1982) y Keshavarz y Jackson (1992). Los parámetros obtenidos en el presente experimento se hallan dentro del rango recomendado para patas criollas, según Grimaud (2005).

La dieta control y las dietas disminuidas en proteína suplementadas con los aminoácidos sintéticos tuvieron los valores más altos en el consumo de metionina y lisina. Se puede observar que cuando los aminoácidos de la dieta son deficientes en metionina y lisina, la ingestión de 
Tabla 1. Formula porcentual de las dietas experimentales y su valor nutritivo calculado

\begin{tabular}{|c|c|c|c|c|c|c|c|c|c|c|c|c|}
\hline \multirow[b]{4}{*}{ Insumos } & \multicolumn{12}{|c|}{ Tratamientos } \\
\hline & \multicolumn{8}{|c|}{ Desarrollo (0-20 Sem.) } & \multirow{2}{*}{\multicolumn{4}{|c|}{$\begin{array}{c}\text { Postura } \\
\text { (21-44 Sem.) }\end{array}$}} \\
\hline & \multicolumn{3}{|c|}{ Inicio } & \multicolumn{5}{|c|}{ Crecimiento } & & & & \\
\hline & 1 & 2 & 3 & 4 & 1 & 2 & 3 & 4 & 1 & 2 & 3 & 4 \\
\hline Maíz (grano amarillo) & 61,86 & 64,66 & 64,64 & 64,65 & 63,50 & 67,10 & 67,09 & 67,04 & 67,57 & 72,73 & 72,73 & 72,60 \\
\hline Harina de soya & 17,24 & 17,35 & 17,35 & 17,35 & 10,00 & 10,00 & 10,00 & 10,00 & 5,41 & 6,30 & 6,30 & 6,30 \\
\hline Subproducto de trigo & 15,00 & 15,00 & 14,87 & 14,70 & 21,00 & 20,296 & 20,19 & 20,09 & 16,11 & 12,85 & 12,71 & 12,60 \\
\hline Harina de pescado (65) & 3,60 & 0,15 & 0,15 & 0,15 & 3,60 & 0,15 & 0,15 & 0,15 & 3,60 & 0,15 & 0,15 & 0,15 \\
\hline Carbonato de calcio & 1,44 & 1,55 & 1,55 & 1,55 & 1,28 & 1,41 & 1,42 & 1,42 & 6,30 & 6,48 & 6,48 & 6,47 \\
\hline Fosfato monocálcico & 0,66 & 1,09 & 1,10 & 1,10 & 0,42 & 0,85 & 0,85 & 0,85 & 0,81 & 1,29 & 1,29 & 1,30 \\
\hline Sal común & 0,10 & 0,10 & 0,10 & 0,10 & 0,10 & 0,10 & 0,10 & 0,10 & 010 & 0,10 & 0,10 & 0,10 \\
\hline $\begin{array}{l}\text { Vitaminas y } \\
\text { microminerales }\end{array}$ & 0,10 & 0,10 & 0,10 & 0,10 & 0,10 & 0,10 & 010 & 0,10 & 0,10 & 0,10 & 0,10 & 0,10 \\
\hline (premix) & -- & -- & 0,14 & 0,14 & -- & -- & 0,10 & 0,10 & -- & -- & 0,14 & 0,14 \\
\hline DL-Metionina, $99 \%$ & -- & -- & -- & 0,16 & -- & -- & -- & 0,15 & -- & -- & -- & 0,24 \\
\hline L-Lisina, $99 \%$ & & & & & & & & & & & & \\
\hline Proteína total & 18 & 16 & 16 & 16 & 15 & 13 & 13 & 13 & 13 & 11 & 11 & 11 \\
\hline $\begin{array}{l}\text { Energía metabolizable } \\
\text { (Mcal } / \mathrm{kg} \text { ) }\end{array}$ & 2,84 & 2,84 & 2,84 & 2,84 & 2,84 & 2,84 & 2,84 & 2,84 & 2,80 & 2,80 & 2,80 & 2,80 \\
\hline Lisina total & 0,91 & 0,74 & 0,74 & 0,90 & 0,73 & 0,56 & 0,56 & 0,71 & 0,58 & 0,42 & 0,42 & 0,66 \\
\hline Metionina total & 0,34 & 0,27 & 040 & 0,40 & 0,30 & 0,24 & 0,32 & 0,32 & 0,27 & 0,21 & 0,35 & 0,35 \\
\hline Metionina * Cistina & 0,61 & 0,54 & 0,68 & 0,68 & 0,54 & 0,46 & 0,56 & 0,56 & 0,47 & 0,40 & 0,54 & 0,54 \\
\hline Calcio & 0,86 & 0,85 & 0,85 & 0,85 & 0,75 & 0,75 & 0,75 & 0,75 & 2,70 & 2,70 & 2,70 & 2,70 \\
\hline Fosforo disponible & 0,38 & 0,38 & 0,38 & 0,38 & 0,33 & 0,33 & 033 & 0,33 & 0,40 & 0,40 & 0,40 & 0,40 \\
\hline Fibra & 4,38 & 4,43 & 4,41 & 4,41 & 4,58 & 4,55 & 4,55 & 4,55 & 3,82 & 3,62 & 3,60 & 3,58 \\
\hline Grasa & 4,00 & 3,89 & 3,89 & 3,89 & 4,18 & 4,00 & 4,00 & 4,00 & 3,89 & 3,76 & 3,75 & 3,75 \\
\hline Sodio & 0,11 & 0,08 & 0,08 & 0,08 & 0,11 & 0,08 & 0,08 & 0,08 & 0,10 & 0,07 & 007 & 0,07 \\
\hline
\end{tabular}

1= Dieta control, $2=$ Dieta disminuida en proteína total sin suplementación de aminoácidos,

3= Dieta disminuida en proteína suplementada solo con DL-Metionina, 4= Dieta disminuida en proteína suplementada con DL-Metionina y L-Lisina.

Los tratamientos fueron:

$\mathrm{T} 1=$ Dieta control.

T2=Dieta disminuida en proteína, sin suplementación.

T3=Dieta disminuida en proteína, suplementada solo con DL- Metionina.

T4=Dieta disminuida en proteína, suplementada con DL-Metionina y L-Lisina.

Tabla 2. Rendimiento productivo de las patas criollas (0-20 semanas)

\begin{tabular}{ccccccc}
\hline \multirow{2}{*}{ Tratamiento } & \multirow{2}{*}{$\begin{array}{c}\text { Peso } \\
\text { corporal } \\
(\mathbf{k g})\end{array}$} & \begin{tabular}{c} 
Alimento \\
\cline { 3 - 6 }
\end{tabular} & $\begin{array}{c}\text { Proteína } \\
(\mathbf{k g})\end{array}$ & $\begin{array}{c}\text { Lisina } \\
\mathbf{( k )}\end{array}$ & $\begin{array}{c}\text { Metionina } \\
(\mathbf{g})\end{array}$ & $\begin{array}{c}\text { Conversión } \\
\text { alimenticia }\end{array}$ \\
1 & $2,51^{\mathrm{ab}}$ & $14,93^{\mathrm{ab}}$ & $2,31^{\mathrm{a}}$ & $112,68^{\mathrm{a}}$ & $45,65^{\mathrm{b}}$ & $5,95^{\mathrm{bc}}$ \\
2 & $2,41^{\mathrm{d}}$ & $15,99^{\mathrm{a}}$ & $2,16^{\mathrm{ab}}$ & $94,35^{\mathrm{b}}$ & $39,18^{\mathrm{c}}$ & $6,64^{\mathrm{a}}$ \\
3 & $2,45^{\mathrm{c}}$ & $15,76^{\mathrm{a}}$ & $2,12^{\mathrm{b}}$ & $92,24^{\mathrm{b}}$ & $52,20^{\mathrm{a}}$ & $6,44^{\mathrm{ab}}$ \\
4 & $2,54^{\mathrm{a}}$ & $14,47^{\mathrm{b}}$ & $1,94^{\mathrm{c}}$ & $106,65^{\mathrm{a}}$ & $47,95^{\mathrm{b}}$ & $561^{\mathrm{c}}$ \\
\hline
\end{tabular}

a, b, c, d: Valores con letra diferente dentro de las columnas difieren significativamente.

1= Dieta control, 2= Dieta disminuida en proteína total sin suplementación de aminoácidos, 3= Dieta disminuida en proteína

suplementada solo con DL-Metionina, 4= Dieta disminuida en proteína suplementada con DL-Metionina y L-Lisina.

estos nutrientes también es deficiente, a pesar de que las aves consumieron más alimento para tratar de cubrir sus necesidades, ante la falta de los aminoácidos esenciales, concordando con los reportes de Andrade et al. (2003). Con ello, se demuestra que los aminoácidos deben ser tomados en cuenta prioritariamente en la formulación de las raciones y deben estar en el nivel recomendado para que las aves los puedan aprovechar y tener un buen rendimiento productivo.

Las aves alimentadas con la dieta disminuida en proteína, pero suplementada con DL-Metionina y L-Lisina, fueron las que ingirieron menos proteína total, a pesar de tener cubiertos los niveles de metionina y lisina en la dieta, lo cual no concuerda con los reportes de Leeson y Summers (1982). Sin embargo, a pesar de tener una baja ingesta de proteína total, este tratamiento fue el más eficiente y demostró que la adición de los aminoácidos sintéticos hasta cubrir los requerimientos del ave, tienen un efecto positivo en la mejora de la conversión alimenticia.

En cuanto al balance de nitrógeno, se encontraron 
Tabla 3. Balance de nitrógeno en las patas criollas en desarrollo (0-20 semanas de edad)

\begin{tabular}{|c|c|c|c|c|}
\hline \multirow[b]{2}{*}{ Tratamientos } & \multicolumn{4}{|c|}{ Característica } \\
\hline & $\begin{array}{c}\text { Consumo } \\
\text { N (g) }\end{array}$ & $\begin{array}{c}\text { Excreción } \\
\text { N (g) }\end{array}$ & $\begin{array}{c}\text { Balance } \\
\text { N (g) }\end{array}$ & $\begin{array}{c}\text { Coeficiente } \\
\text { Metabolización } \\
\text { Aparente } \\
\text { N }(\%)\end{array}$ \\
\hline 1 & $5,4160^{\mathrm{a}}$ & $2,8256^{\mathrm{a}}$ & 2,5904 & $47,80^{\mathrm{d}}$ \\
\hline 2 & $4,7664^{\mathrm{d}}$ & $2,2176^{\mathrm{d}}$ & 2,5488 & $53,66^{\mathrm{a}}$ \\
\hline 3 & $4,8192^{\mathrm{c}}$ & $2,3952^{\mathrm{c}}$ & 2,4240 & $50,21^{\mathrm{b}}$ \\
\hline 4 & $4,8400^{b}$ & $2,4448^{b}$ & 2,3957 & $49,43^{\mathrm{c}}$ \\
\hline
\end{tabular}

Tabla 4. Rendimiento productivo de las patas criollas en postura (21-44 semanas)

\begin{tabular}{|c|c|c|c|c|c|c|c|c|c|c|}
\hline \multirow[b]{2}{*}{ Tratamientos } & \multicolumn{4}{|c|}{ Consumo/Ave } & \multirow{2}{*}{$\begin{array}{c}\text { Total } \\
\text { Huevos/ave }\end{array}$} & \multirow{2}{*}{$\begin{array}{l}\text { Peso Prom. } \\
\text { Huevo (g) }\end{array}$} & \multirow{2}{*}{$\begin{array}{c}\text { Masa } \\
\text { Huevos } \\
(\mathrm{Kg})\end{array}$} & \multirow{2}{*}{$\begin{array}{c}\% \\
\text { Postura }\end{array}$} & \multirow{2}{*}{$\begin{array}{l}\text { Conversión } \\
\text { Alimenticia }\end{array}$} & \multirow{2}{*}{$\begin{array}{c}\text { Peso Final } \\
(\mathrm{Kg})\end{array}$} \\
\hline & $\begin{array}{c}\text { Acumulado } \\
(\mathrm{Kg})\end{array}$ & $\begin{array}{l}\text { Proteína } \\
(\mathrm{Kg})\end{array}$ & $\begin{array}{l}\text { Lisina } \\
(\mathrm{g})\end{array}$ & $\begin{array}{l}\text { Metionina } \\
(\mathrm{g})\end{array}$ & & & & & & \\
\hline 1 & $26,64^{\mathrm{c}}$ & $3,46^{\mathrm{a}}$ & $266,47^{\mathrm{a}}$ & $106,59^{\mathrm{a}}$ & $50,00 \mathrm{a}$ & $68,33^{\mathrm{a}}$ & $3,43^{\mathrm{a}}$ & $30,65^{\mathrm{a}}$ & $7,85 \mathrm{c}$ & $2,53^{\mathrm{a}}$ \\
\hline 2 & $31,22^{\mathrm{a}}$ & $3,43^{\mathrm{a}}$ & $131,13 \mathrm{c}$ & $65,57^{\mathrm{d}}$ & $23,44^{\mathrm{c}}$ & $65,43^{\mathrm{a}}$ & $1,54^{\mathrm{c}}$ & $15,25^{\mathrm{c}}$ & $20,12^{\mathrm{a}}$ & $2,32^{\mathrm{b}}$ \\
\hline 3 & $28,60^{\mathrm{b}}$ & $3,14^{\mathrm{b}}$ & $120,13^{\mathrm{d}}$ & $100,11^{\mathrm{b}}$ & $33,72^{\mathrm{b}}$ & $65,93^{\mathrm{a}}$ & $2,22^{\mathrm{bc}}$ & $21,89^{b}$ & $12,95^{\mathrm{b}}$ & $2,73^{\mathrm{b}}$ \\
\hline 4 & $25,82^{\mathrm{c}}$ & $2,84^{\mathrm{c}}$ & $170,46^{\mathrm{b}}$ & $90,40^{\mathrm{c}}$ & $42,44^{\mathrm{ab}}$ & $66,84^{\mathrm{a}}$ & $2,83^{\mathrm{ab}}$ & $27,56^{\mathrm{ab}}$ & $9,23^{\mathrm{c}}$ & $2,52^{\mathrm{a}}$ \\
\hline
\end{tabular}

a, b, c, d: Valores con letras diferentes dentro de las columnas difieren significativamente.

1= Dieta control, 2= Dieta disminuida en proteína total sin suplementación de aminoácidos,

3= Dieta disminuida en proteína suplementada solo con DL-Metionina, 4= Dieta disminuida en proteína suplementada con DL-Metionina y

L-Lisina.

diferencias altamente significativas (Tabla 3). Las aves que consumieron la dieta control tuvieron la mayor ingesta y excreción de nitrógeno, pero el menor porcentaje de metabolicidad. El balance de nitrógeno resultó positivo para todos los tratamientos; las aves han tenido suficiente nitrógeno para su mantenimiento y la producción de huevos. Por otro lado, la suplementación con DLMetionina y HCL-Lisina no mejoró el nivel de nitrógeno obteniéndose menores balances de este.

Las aves que recibieron la dieta baja en proteína y sin suplementación tuvieron el mayor porcentaje de metabolicidad de nitrógeno, por lo que han retenido mayor cantidad de nitrógeno para tratar de cubrir sus necesidades de mantenimiento y producción. Estos resultados concuerdan con los hallazgos de Rizzo et al. (2004).

En la Tabla 4, se pueden observar los resultados para la etapa de postura. Con relación al consumo de alimento, se encontraron diferencias significativas y las aves alimentadas con la dieta disminuida en proteína suplementada con los dos aminoácidos sintéticos tuvieron el menor consumo. Sin embargo, la ingesta de proteína, lisina y metionina fue mayor solo en las aves alimentadas con la dieta control, lo cual indica que las aves ingieren los nutrientes adecuadamente cuando estos se suministran de acuerdo con sus necesidades. Por otro lado, se encontraron diferencias altamente significativas para el número total de huevos por pata, masa de huevos, porcentaje de postura y conversión alimenticia, a favor de la dieta control y la dieta disminuida en proteína y suplementada con DL-Metionina y L-Lisina; estos resultados concuerdan con Leeson y Summers (1982) y con Maurice et al. (1982). La deficiencia de los aminoácidos metionina y lisina en dietas disminuidas en proteína total puede disminuir el rendimiento productivo de las aves en postura, pero corrigiendo los niveles de estos aminoácidos hasta cubrir los requerimientos, se puede alcanzar el mismo rendimiento.

Para el peso promedio de los huevos y el peso corporal final, no se encontraron diferencias significativas; lo cual indica que la falta de los dos aminoácidos no ha influido en estos parámetros en las patas criollas, que concuerda con Andrade et al. (2003).

Los resultados obtenidos con la dieta control y la dieta disminuida en proteína y suplementada con DL-Metionina y L-Lisina, se hallan dentro de los valores obtenidos y preestablecidos para la raza criolla hasta un año de edad, reportados por Muscari (1985) y Pajuelo (2002).

Las aves que fueron alimentadas con las dietas control y la dieta baja en proteína, pero con suplemento DL- 
Metionina y HCL-Lisina, fueron las más eficientes. Estos resultados concuerdan con Maurice et al. (1982). Por otro lado, las aves alimentadas con los niveles disminuidos de proteína total y sin suplemento de los dos aminoácidos, han consumido más alimento, probablemente para tratar de cubrir sus necesidades de aminoácidos en la fase de postura.

En cuanto al balance de nitrógeno, se encontraron diferencias altamente significativas (Tabla 5). Las aves que consumieron la dieta control tuvieron la mayor ingestión y excreción de nitrógeno, pero el menor porcentaje en metabolismo. El balance de nitrógeno resultó positivo para todos los tratamientos, en efecto, las aves han tenido suficiente nitrógeno para su mantenimiento y la producción de huevos. Por otro lado, la suplementación con DLMetionina y HCL-Lisina no mejoró el nivel de balance de nitrógeno y se obtuvo valores menores. Las aves sometidas a la dieta baja en proteína y sin suplementos tuvieron el mayor porcentaje de metabolismo de nitrógeno, por tanto han retenido mayor cantidad de este elemento para tratar de cubrir sus necesidades de mantenimiento y producción, concordando con Rizzo et al. (2004).

Se determinó el costo de desarrollo por pata y el número total de huevos producidos asumiendo que son fértiles (Tabla 6). El menor costo de alimentación por pata desarrollada se consiguió con la dieta disminuida en proteína con suplementos de DL-Metionina y L-Lisina. Sin embargo, en la etapa de postura, los mayores beneficios por huevos producidos se consiguieron con las aves alimentadas con la dieta control, siendo negativa la retribución económica cuando se suministró a las aves la dieta disminuida en proteína total y sin suplementación. Los precios están referidos al mes de mayo del 2013.

\section{Conclusiones}

Los suplementos de DL-Metionina y L-Lisina a las dietas disminuidas en proteína total de las patas criollas, mejoró los parámetros evaluados y el costo por ave en la etapa

Tabla 5. Balance de nitrógeno en las patas criollas en postura (21-44 semanas de edad)

\begin{tabular}{ccccc}
\hline & \multicolumn{3}{c}{ Característica } \\
\cline { 2 - 5 } Tratamientos & $\begin{array}{c}\text { Consumo } \\
\mathbf{N}(\mathbf{g})\end{array}$ & $\begin{array}{c}\text { Excreción } \\
\mathbf{N}(\mathbf{g})\end{array}$ & $\begin{array}{c}\text { Balance } \\
\mathbf{N}(\mathbf{g})\end{array}$ & $\begin{array}{c}\text { Coeficiente } \\
\text { Metabolización Aparente } \\
\mathbf{N}(\mathbf{\%})\end{array}$ \\
\hline 1 & $2,0432^{\mathrm{a}}$ & $1,1312^{\mathrm{a}}$ & 0,9120 & $44,64^{\mathrm{d}}$ \\
2 & $1,7408^{\mathrm{d}}$ & $0,8768^{\mathrm{d}}$ & 0,8640 & $49,63^{\mathrm{a}}$ \\
3 & $1,7728^{\mathrm{c}}$ & $0,9296^{\mathrm{c}}$ & 0,8432 & $47,56^{\mathrm{b}}$ \\
4 & $1,7808^{\mathrm{b}}$ & $0,9642^{\mathrm{b}}$ & 0,8160 & $45,82^{\mathrm{c}}$ \\
\hline
\end{tabular}

a, b, c, d: Valores con letra diferente dentro de las columnas difieren significativamente.

1= Dieta control, 2= Dieta disminuida en proteína total sin suplemento de aminoácidos, 3= Dieta disminuida en proteína con suplemento solo de DL-Metionina, 4= Dieta disminuida en proteína con suplemento solo de DLMetionina y L-Lisina.

Tabla 6. Retribución económica por ave desarrollada y por la producción de huevos

\begin{tabular}{|c|c|c|c|c|}
\hline Desarrollo (0-20 Sem.) & 1 & 2 & 3 & 4 \\
\hline $\mathrm{N}^{\circ}$ patitos & 60 & 60 & 60 & 60 \\
\hline Precio/patito (S/.) & 5 & 5 & 5 & 5 \\
\hline Costo total de patitos $(\mathrm{S} /)$. & 300 & 300 & 300 & 300 \\
\hline Total alimento consumido (kg) & 895,56 & 959,76 & 945,42 & 868,26 \\
\hline Precio/kg de alimento (S/.) & 1,30 & 1,18 & 1,23 & 1,28 \\
\hline Costo por alimentación $(\mathrm{S} /)$. & $1.164,23$ & $1.132,52$ & $1.162,87$ & $1.111,37$ \\
\hline Costo alimentación / pata en levante & 19,40 & 18,88 & 19,38 & 18,52 \\
\hline \multicolumn{5}{|l|}{ Postura (21-44 sem.) } \\
\hline Consumo total de alimento & 159,88 & 187,33 & 171,61 & 154,96 \\
\hline Precio por kg de alimento (S/.) & 1,08 & 1,04 & 1,05 & 1,06 \\
\hline Costo total del alimento & 172,67 & 194,82 & 180,19 & 164,26 \\
\hline Número total de huevos & 300 & 144 & 204 & 270 \\
\hline Precio del huevo por unidad (S/.) & 1,00 & 1,00 & 1,00 & 1,00 \\
\hline Total por venta de huevos & 300,00 & 144,00 & 204,00 & 270,00 \\
\hline Retribución económica (S/.) & 127,33 & $-50,82$ & 23,81 & 105,74 \\
\hline
\end{tabular}

$1=$ Dieta control, $2=$ Dieta disminuida en proteína total sin suplemento de aminoácidos, $3=$ Dieta disminuida en proteína con suplemento solo de DL-Metionina, 4= Dieta disminuida en proteína con suplemento solo de DLMetionina y L-Lisina. 
de desarrollo. También, se tuvieron los mejores resultados en los parámetros de la etapa de postura, a excepción del peso promedio de huevos y del peso final de postura; sin embargo, no se tuvo una retribución económica positiva por la venta de huevos.

Las aves alimentadas con la dieta control tuvieron la mayor ingestión y excreción de nitrógeno, pero el menor porcentaje de metabolismo de nitrógeno; a pesar de ello, las aves alimentadas con la dieta baja en proteína y sin suplemento de aminoácidos, tuvieron una mayor utilización del nitrógeno.

El uso de los aminoácidos sintéticos es recomendado principalmente en la etapa de desarrollo por el mérito económico encontrado y los mayores rendimientos en la producción. En la fase de postura se tendría que investigar el nivel máximo de disminución de proteína total para una suplementación adecuada de los aminoácidos sintéticos con el fin de cubrir las necesidades de las patas criollas.

\section{Literatura citada}

Ajinomoto Biolatina Ind. y Compañía Ltda. 2005. Informe de trabajos de investigación. Boletín técnico. Recuperado de www.lysine.com.br

Andrade, L.; Leandro, N. y Stringhini, J. 2003. Suplementación de Aminoácidos en la dieta de ponedoras comerciales. Brasil: Universidad Federal de Goias-ufg.

Calzada, J. 1981. Métodos Estadísticos para Investigación. (4ta edición). Lima, Perú: Editorial Milagros S.A. UNALM.

Church, D. 1992. Fundamentos de Nutrición y Alimentación de Animales. (1ra edición). México: Edit. Limusa.

INSTITUT NATIONAL DE LA RECHERCHE AGRONOMIQUE [INRA]. 1984. Alimentación de los animales monogástricos. Madrid, España: Ed. MundiPrensa.

Keshavarz, y Austic, R. 1985. An investigation concerning to possibility of supplemental methionine with choline practical laying rations. Poultry Science, 64: 114-118.

Keshavarz, K. y Jackson, M. 1992. Performance of growing pullets and Laying hens fed low protein, amino acid-supplemented diets. Poultry Science, 71: 905-918.

Leclercq, B. 1998. Specific effects of lysine on broiler production. Poultry Science, 77: 118-123.

Leeson, J. y Summers, J. 1982. Use of single stage low protein diets for growing leghorn pullets. Poultry Science, 61: 1684-1691.

Lillie, R. y Denton, C. 1974. Effect of nutrient restriction on White Leghorns in the grower and subsequent layer periods. Poultry Science, 45: 810-818.

Maurice, D.; Hughes, B.; Jones, J. y Weber, M. 1982. The effect of reverse protein and low protein feeding regiments in the rearing period on pullet growth and subsequent performance. Poultry Science, 62429.

Muscari, J. 1985. Incubabilidad y ritmo de crecimiento en patos criollos. Resumen VII Reunión Científica del APPA. Huancayo, Perú.
Pajuelo, V. 2002. Efecto de la relación del número de hembras por macho en el rendimiento reproductivo de patos criollos (Cairina moschatadoméstica L.). (Tesis). Universidad Nacional Agraria La Molina.

Rizzo, M.; De Ponti, B.; Silva, F.; Rombola, G. y De Faria, D. 2004. Efecto de diferentes niveles de proteina cruda y lisina sobre la ingestión y excreción de nitrógeno de ponedoras comerciales. Sao Paulo, Brasil: Universidad de Sao Paulo-Pirassununga-SP.

Rojas, S. 1994. Nutrición Animal Aplicada. Lima, Perú: Editorial UNALM. 